\title{
Ideological Identity Statuses of students of Grades 8-11
}

\author{
Basma Salim Al-Balushi ${ }^{1}$, Abdulqawi Salim Alzubaidi ${ }^{2}$ and Ali Mahdi Kazem ${ }^{2 \star}$ \\ ${ }^{1}$ Ministry of Education, Oman \\ ${ }^{2}$ Department of Psychology, Sultan Qaboos University, Oman
}

\begin{abstract}
The study aimed at discovering the ideological identity statuses (achievement, moratorium, foreclosure and diffusion) among Omani students of grades 8-11 in basic education and post basic education schools in Muscat Governorate. It also aimed at identifying whether there are differences according to Gender and Grade variables. To achieve these aims the Ego Identity Status measure was applied to 740 male and female students. The results of the study showed that the most common status was identity achievement. In addition, there were statistically significant differences in identity achievement status according to the gender variable favoring female students. While the foreclosure and diffusion identities were favored by male students. Furthermore, there were statistically significant differences according to grade levels in moratorium status favoring grade 8 , whereas, foreclosure status was favored by grades 8 and 9 . Finally, there were statistically significant interactions between grade and gender variables favoring grade 8 male students and grade 11 female students. The study concluded with a number of recommendations, such as; reinforcing identity culture and communicating its importance to school and university students within a targeted social group.
\end{abstract}

\section{Introduction}

Identity formation is an important aspect of nations and peoples all over the world because of the rapid change taking place in all aspects of life: psychological and social effects that lead to changing individuals' thinking, self-awareness and concept of self.

Erikson's [1] construct of identity development is conceptualized as a psychosocial task. The social focus of the construct makes it a useful theoretical framework to use in an investigation where the social context of intrapersonal (ego) development is important to the researcher [2], formulated an eight stage theory of personality development, extending from birth to old age. The developmental task that has to be resolved during the adolescent stage, the fifth psychosocial stage, is identity formation versus role confusion [3]. Erikson $[1,2]$ has given a rich description of identity development and his theoretical work has stimulated a considerable number of empirical investigations over the past three and a half decades. A point of criticism directed at Erikson's work by various authors (for example, [4-6] is that Erikson's metaphorical writing style has led to a diversity of definitions (of identity) and methodological approaches.

According to Erikson's theory, the concept of identity imagines a building that consists of many psychological components or dimensions integrated dynamically and which change gradually with age and experience so that the individual can gain a clear and coherent sense of self-knowledge, and what an individual could be in life [7].

Through previous definition, we can reach the conclusion that identity is an integrated interaction between Ego and self which leads to satisfying the needs of the individual in the light of the outside world and the individual's beliefs and values as well as organizing the process of Adjustment and Psychosocial health.

Identity has been operationalized for measurement in a variety of ways, but by far the most popular is that of Marcia [8]. Marcia [9] which broke the identity formation task into two parts: exploration and commitment. The exploration process reflects a genuine examination of and experimentation with alternative directions and beliefs [10]. Usually, this process involves the questioning of past childhood positions and some form of departure from them. Commitment refers to "the degree of personal investment the individual exhibits" [8]. These two parts are combined to form four identity statuses representing the different ways in which people attempt to address identity issues: Achievement, Moratorium, Foreclosure, and Diffusion. Because the identity status paradigm is well known, an extensive review is not provided here; instead, readers are referred to $[11,12]$ for a recent review.

James Marcia has classified individuals into four statuses after identifying the areas of identity by using a semi-structured interview tool. The four areas identity are, concerned with religion, occupation, policy and life style. The appearance of ideological identity statuses depend on the appearance or absence of identity crisis and commitment. Marcia's Model of Ideological Identity represents a real development of Erikson's theory on forming identity in adolescence. Each status reflects the individual's ability to deal with the problems associated with his aims and roles so he can reach fixed meaning for himself. Throughout continuous studies, Marcia determined four statuses of Ego characterized by variable of dynamic nature [9]. In other words, the ego identity continuously changes. Marcia [8,9] has identified Ideological Identity Statuses as: psychological conditions experienced by the individual during adolescence and adulthood to specify his identity. They represent the dimensions of exploration, crisis and commitment they also represent the outputs of a developmental evolutionary process which form identity and the personal structural characteristics of the personality. This was specified in four statuses:

Identity Achievement: A status in which the adolescent has made an independent compromise between internal needs and social demands. Identity Moratorium: A status in which the adolescent has postponed any decision or compromise, but considers all points of view.

"Corresponding Author: Prof. Ali Mahdi Kazem, Department of Psychology, Sultan Qaboos University, Oman; E-mail: amkazem@squ.edu.om

Citation: Al-Balushi BS, Alzubaidi AS, Kazem AM (2015) Ideological Identity Statuses of Students of Grades 8-11. Int J Psychol Behav Anal 1: 106. doi: http:// dx.doi.org/10.15344/2455-3867/2015/106

Copyright: () 2015 Al-Balushi et al.. This is an open-access article distributed under the terms of the Creative Commons Attribution License, which permits unrestricted use, distribution, and reproduction in any medium, provided the original author and source are credited. 
Identity Forclosure: A status in which the adolescent unreflectively adopts parental standards.

Identity Diffusion: A status in which the adolescent has made neither a decision nor a compromise, nor is there an active consideration of options.

Identity crisis is one of the developmental difficulties facing the individual in adolescence, where it appears at this stage as a psychological dimension. Its positive aspect is in achieving identity and its negative aspect results in identity diffusion. That is to say that identity crisis in the stage of adolescence has two poles: The first pole is identity achievement and it is the positive component of identity crisis. The second pole is identity diffusion which is the negative component of this crisis [13].

The results of many studies show that identity diffusion status at the age of 12 for males is most common between statuses. There is a transition to the individual from identity moratorium status to identity achievement status at the age of 18 . Yet most individuals at the age of 21 are classified as having achieved their identity. That shows that the biggest change in identity happens between 18 and 21 years and that change is from foreclosure or diffusion identity to achievement identity [14].

Marcia believes that there is a sequential arrangement of ideological identity statuses which progress in a linear trend from steady diffusion identity to foreclosure or moratorium identity. It moves from moratorium ascending to identity achievement [15]. Many researchers have commented on the chronological order of Marcia's identity status; that it is not always right to say that identity status is fixed but open and subject to change and transformation. It could be recognized as a developmental evolutionary process but it is not serial ordinal except for the status of identity moratorium. So identity achievement cannot be achieved without exploration and research [16].

Identity develops gradually during adolescence through organized increases in the status of achievement and decreases in the status of diffusion. However, the endpoint may be achievement or foreclosure. Jan Kroger has defined the unexpected theoretical changes in identity status from the developing status which is the most mature, to identity status which is the least mature, which he called (Regression) when the individual sticks to the commitment to values and rejects exploring new possibilities [17].

Erikson has not specified differences between males and females in identity development and he supposed that identity development crises happen in the same order for both [18]. Other studies indicate that gender is a statistical significant variable in specifying ideological identity statuses as in Albert's study [19] that indicated the ideological identity of females develop more strongly than that of males. That study shows that identity formation of females is more complicated than that of males. It also shows that males have more diffusion and foreclosure statuses than females in the area of religion but have more identity achievement in policy and profession. These findings are supported by the study of Echabe [20] who sees that males specify their identity basically by their professions while females specify their identity basically on success in establishing human relations, especially emotional relations.

Although researchers still use Marcia's [8] semi-structured interview, others have looked for ways to make the measurement of identity statuses less time-consuming and less expensive. Adams and Fitch [15] devised the Objective Measure of Ego Identity Status (OMEIS) to accomplish this task. In addition to its utility in reducing time and expense, the OMEIS also allows examination of continuous scores for each of the identity statuses. This affords a more complex identity picture that includes information on transition between stages. Both Marcia's [8] original interview and the OMEIS measure identity status in the ideological domain, but Grotevant and colleagues [21] argued that identity also consists of interpersonal aspects and added the elements of friendship, dating, and sex roles to Marcia's [8] interview and to the OMEIS. This longer version of the OMEIS is referred to as the Extended OMEIS (EOMEIS). In addition to these content areas Grotevant and Adams [15] added an ideological component called "philosophical style" to reflect Erikson's [1] writings on the formation of an individual or philosophical lifestyle. They also added the topic of "recreation" to the interpersonal domain. In the most recent revision, referred to as the EOMEIS-2, Bennion and Adams [21]) revised the original EOMEIS interpersonal questions to make them less ambiguous and more consistent. Numerous studies have tested and affirmed the validity of the OMEIS and its revised versions $[5,22]$ review of this literature.

Many studies have addressed the topic of identity from different perspectives and its relationship with many variations when university students are sampled. Yet modern educational studies in the Arab World are rare-and at the limits of science researchers. One of those studies for example is the study done by Cakir and Ayden [23] which aimed to discover the differences between the four statuses of identity. The study employed the Objective Measure of Ego Identity Status [21]. It was a 64-item questionnaire probing the ideological and interpersonal domains of identity. Participants responded to a 6-point Likert scale ranging from 1 (strongly disagree) to 6 (strongly agree). Cronbach's alpha reliability scores for identity statuses were $(0.57$ 0.84). This study was applied to 403 students in grade 11 in Ankara schools whose ages ranged from (16-19) years. The results showed differences in identity achievement status for females and identity foreclosure for males.

Bergh and Erling's [24] study aimed to examine Ego Identity Status among Swedish adolescents using the EOM-EIS-II. Identity status scores and distributions were examined in 222 (108 female, 114 male) Swedish high school students. The presence or absence of exploration and commitment were assessed within the following areas: occupation, politics, life style, recreational choices, friendship, and gender roles. The results have shown the extent of diffusion identity status between the individuals of the sample and that there are differences in moratorium identity status for females and diffusion identity for males. It also showed there were no differences between males and females in the status of identity achievement.

The study of Kountouri and Hurry [25] was seeking the relationship between identity status and its areas (political, religious and occupational) and considered context and gender as integral parts of identity. The Extended Objective Measure of Ego Identity Status (EOMEIS-2) Scale was used to collect data. It consisted of 24 items which measured the four statuses of identity: achievement, moratorium, foreclosure and diffusion. For each status there were three areas which are occupational, political and religion). Cronbach's alpha reliability scores for identity statuses were $(0.46-0.66)$. The study sample consisted of 1038 Greek Cypriot adolescents in 
secondary schools. The results indicated that Greek adolescents are characterized by political identity more so than the Americans. The results did not show any differences in occupational identity but there are differences in identity in general, between the teenagers' results from the gender variable; females were more inclined to moratorium while males were more diffusion oriented and there were the same differences for the religious, political and occupational identities.

The study of Mullis, Mullis and Graf [26] investigated the differences in identity formation among 434 male and female American and Indian students who were aged 13-18, by applying the extended objective measure for identity statuses (EOMEIS-2) which consists of 64 items between ideological and interpersonal identity statuses. Tests of reliability for ideological identity have produced alpha coefficients that were as follows achievement 0.62 , moratorium 0.75 , foreclosure 0.75 and diffusion 0.62 . The Results showed that adolescents in Indian Schools are characterized by a foreclosure identity while adolescents in American schools are characterized by the diffusion identity. Also the males are characterized by diffusion identity compared to females. The youngest adolescents (13-15) are characterized by foreclosure identity in comparison with the older adolescents (16-18) but there are no differences between adolescents in achievement identity.

According to the previous context, the study problem is summarized in the following way:

1. The school stage between grades $8-11$ is a critical stage for the individual because it coincides with adolescence which is full of challenges that individuals may face. Adolescence is associated with constructing the individual's personality and achieving an identity and that leads him to seek an identity which distinguishes him from the identities of others. Unless an individual achieves his identity, he will be led to identity confusion, alienation and the lack of goals. It also leads to the inability to plann, choose future goals and the inability to work.

2. There is a lack of Arab studies which addresses the statuses of ideological identities of students in grades 8-11 most studies are confined to those of students in universities and colleges.

3. Some studies were applied to students in Sultan Qaboos University. As Alkhawaja's study [27] has shown, many students of the university suffer from difficulty in making appropriate occupational decisions and lack Vocational Maturity. Thus making them dependent on others to make their decisions for them and not take responsibility. That inspired the researchers to study the status of schools students' ideological identity of because of its relationship to the main features of personality as self-concept, ethical behavior and psychosocial adjustment.

4. The researchers in this study observed that Omani student's faces a tremendous knowledge revolution and that made some of them reject the laws and regulations of the school and question them. That drives the researches to ask for the reasons behind this rejection; whether it was from psychological, social, or cognitive reasoning. This knowledge may affect one's identity in many areas such as the choice of a suitable academic specialization. That is because he himself, does not know, what he will be in the future and has no rich fund of experience to help him to explore his (Ego) in addition to dealing with the transitions of identity during adolescence.

This study aims to answer the following questions:

1. What is the level of ideological identity in Omani Student in grades 8-11 for ideological identity statuses? Which statuses are considered to be the most common ideological identity?

2. Are there statistically significant differences in the ideological identity statuses related to the two variables of gender and grade?

\section{Methods}

\section{Participants and procedures}

The sample of the study consisted of 740 male and female students from grades 8 to 11,390 males 350 females. They were chosen as Multi-Stage random sample [28]. by an approximate 3\%. Three states were chosen randomly (ALAmerat, Mascat and ALSeeb) then four schools were chosen from each state. Two schools for males and two schools for females were chosen and that was followed by choosing the number of classrooms located in each school chosen. Access to the schools was obtained from the Ministry of Educations schools granted access to grade 11 and 12 students. Participants were informed of the purpose of the study and that their participation was voluntary. All students agreed to participate and they were also told their responses would remain anonymous and neither school staff nor parents would have access to the data. The students were also informed that participation in the study would not influence their grades. The study questionnaires were administered during class sessions and research assistants took over the classes during administration. The administration of the questionnaires took about 15-25 minutes. Study data were analyzed by using SPSS.

\section{Materials}

The researchers the current study prepared the questionnaire to match the culture of Omani society; by depending on the previous studies that addressed the subject of identity as $[4,21]$ as well as reading the measures used in and quotationing from some items to reach 48 items divided into four statuses (achievement, moratorium, foreclosure and diffusion) Only in the domain of ideological identity was the response modified on the three point scale to match the sample of the study and to be more specific The measure has not got a total score as the score of every status is treated separately by using the arithmetic average of each status score and comparing it with the theoretical average (The total of the highest mark and the lowest mark divided in two).

To ensure of reliability ideological identity statuses indicators, a sample of 160 male and female students in grades 8-11 was used. The coefficient of stability is done by re-applying with a time lag of two weeks between the first and second application. A Pearson correlation coefficient was counted between the initial estimates of the sample members in the two applications. Correlation coefficient values ranged between (.353-.627) on person correlation coefficient for the four statuses. Cronbach alphas reported as coefficients values ranged between (.466 -.622) for the four statuses.

\section{Results}

The answer to the first question: "What is the level of ideological 
identity in Omani Student in grades 8-11 for ideological identity statuses? Which statuses are considered to be the most common ideological identity? Was through calculating the mean and the standard deviations were for the total sample for every status of ideological identity statuses. The actual means of the sample were compared with the theoretical mean of the measure (the total of the highest and lowest score divided in two) which is 2 , as the increase of the actual mean over 2 means a high level of the sample students of that status and vice versa. And that is by using T-Test for one sample, results are presented in Table 1.

\begin{tabular}{|l|l|l|l|l|l|l|}
\hline$\#$ & $\begin{array}{l}\text { Ideological } \\
\text { Identity Status }\end{array}$ & $\mathrm{M}$ & $\mathrm{SD}$ & $\mathrm{t}$ & $\mathrm{Sig}$. & Effect size \\
\hline 1 & $\begin{array}{l}\text { Identity } \\
\text { Achievement }\end{array}$ & 2.697 & .273 & 69.39 & .001 & .931 \\
\hline 2 & $\begin{array}{l}\text { Identity } \\
\text { moratorium }\end{array}$ & 2.302 & .274 & 3.08 & .001 & .741 \\
\hline 3 & $\begin{array}{l}\text { Identity } \\
\text { Foreclosure }\end{array}$ & 1.962 & .371 & $2.82-$ & .005 & .201 \\
\hline 4 & $\begin{array}{l}\text { Identity } \\
\text { Diffusion }\end{array}$ & 1.890 & .323 & $9.25-$ & .001 & .322 \\
\hline
\end{tabular}

Table 1: The results of "T- Test" for one sample to compare means the actual of ideological Identity Status theoretical mean in descending $\operatorname{order}(n=740)$.

It is observed in Table 1 that the mean of the ideological identity achievement status is higher than the theoretical mean, and the ideological identity moratorium status comes in second place. That means that the standards of achievement and moratorium identity of the sample members is high. While the mean of the foreclosure and diffusion identity is lower than the theoretical mean which shows that the standard of foreclosure and diffusion is low. The researchers find these results support Erikson's supposition that both the ideological identity achievement and the ideological identity moratorium statuses represent advanced statuses of identity. And that the statuses of diffusion and foreclosure represent negative statuses.

To be sure, the difference significance between the circles of the collected values to allow ordering the averages and for recognizing the most common status in the ideological identity statuses. ANOVA with Repeated Measures was used for all the ideological identity statuses as table 2 shows.

According to the results shown in table 2, there are statistically significant differences at a level of less than or equal (.05) between the ideological identity statuses and for specifying the differences in the statically significant ideological identity statuses. The Sidak-Test was done for the bilateral comparisons between the means. The results of

\begin{tabular}{|l|l|l|l|l|}
\hline Source & SS & MS & $\mathrm{F}_{(3,2217)}$ & Sig. \\
\hline Between groups & 303.692 & 101.231 & 1259.457 & $\leq 0.001$ \\
\hline Within groups & 178.195 & .080 & & \\
\hline
\end{tabular}

Table 2:The results of analysis of variance with repeated measurements of the significance of differences between the means of ideological identity status.

Sidak Test indicated the highest means for identity achievement status whose mean was (2.697) and identity moratorium status came second (2.302) while the lowest means were for the statuses of foreclosure and diffusion whose means were respectively (1.962) and (1.890).

To answer the second question, "Are there statistically significant differences in the ideological identity statuses related to the two variables of gender and grade?" The means and standard deviations were extracted to estimate the study sample of members in the four ideological identity statuses according to the two variables of gender and grade. As Table 3 shows.

The multivariate Analysis of variance (MANOVA) used to determine the significance of the main and secondary effects. The results of the analysis showed that the value of (Wilks Lambda) for gender is $0.923(\mathrm{~F}=15.188$, sig $=0,000$ and $\mathrm{P}=0.077)$. As the grade was valued at $0.934(\mathrm{~F}=4.182$, sig $=0.000$ and $\mathrm{P}=0.022)$. The value of Wilks Lambda according to the interaction between gender and grade was $0.972(\mathrm{~F}=1.756, \mathrm{sig}=0.050, \mathrm{P}=0.010)$ and it is a statistical significance at a standard of less than 0.050 and to specify the significant ideological identity statuses in variables of grade and gender and their interaction, the statistical analysis procedures were colmated by multivariate Analysis of variance as Table 4 shows.

Table 4 indicates that the calculated values $(\mathrm{F})$ in gender variable is of statistical significance at a standard less than (0.05) in all statuses of ideological identity except the moratorium status of identity, and by revising the means in Table 3, the results indicated a slightly high mean in the status of identity achievement for females which was (2.734) in comparison with the males (2.673). While in the statuses of foreclosure and diffusion identity, there were statistically significant differences for males; their means were respectively (2.045) and (1.926) in comparison with females $(1.872)$ and $(1,852)$ but the effect of gender in the statuses of (achievement, foreclosure and diffusion) in spite of its signification, was small as it is shown through the value Partial Eta Squared. This proves the existence of very small differences between males and females in the statuses of ideological identity (achievement, foreclosure and diffusion).

\begin{tabular}{|c|c|c|c|c|c|c|c|c|c|c|}
\hline \multicolumn{2}{|c|}{ Variables and levels } & \multirow{4}{*}{$\begin{array}{l}\text { N } \\
\\
383\end{array}$} & \multicolumn{8}{|c|}{ Ideological Identity Status } \\
\hline & & & \multicolumn{2}{|c|}{ Diffusion } & \multicolumn{2}{|c|}{ Foreclosure } & \multicolumn{2}{|c|}{ Moratorium } & \multicolumn{2}{|c|}{ Achievement } \\
\hline & & & M & M & SD & M & SD & M & SD & SD \\
\hline \multirow[t]{2}{*}{ Gender } & Males & & 2.673 & 2.299 & .282 & 2.045 & .288 & 1.926 & .378 & .339 \\
\hline & Females & 357 & 2.724 & 2.307 & .262 & 1.872 & .258 & 1.852 & .343 & .301 \\
\hline \multirow[t]{4}{*}{ Grade } & Eighth & 162 & 2.706 & 2.357 & .230 & 2.078 & .264 & 1.916 & .358 & .298 \\
\hline & Ninth & 206 & 2.696 & 2.308 & .289 & 1.995 & .276 & 1.895 & .387 & .355 \\
\hline & Tenth & 181 & 2.675 & 2.247 & .306 & 1.887 & .283 & 1.884 & .379 & .316 \\
\hline & Eleven & 191 & 2.715 & 2.304 & .258 & 1.897 & .263 & 1.869 & .329 & .315 \\
\hline
\end{tabular}

Table 3: Means (M) and standard deviations (SD) to estimates the study sample in ideological identity status, according to the variable of gender and grade $(n=740)$. 
Page 5 of 7

\begin{tabular}{|c|c|c|c|c|c|c|c|}
\hline Source & $\begin{array}{l}\text { Ideological } \\
\text { Identity Status }\end{array}$ & Sum of Squares & $\mathrm{df}$ & Mean Square & $\mathrm{F}$ & Sig & Partial Eta ${ }^{2}$ \\
\hline \multirow[t]{4}{*}{ Gender } & Achievement & .504 & 1 & .504 & 6.820 & .009 & .009 \\
\hline & Moratorium & .021 & 1 & .021 & .287 & .592 & .000 \\
\hline & Foreclosure & 5.826 & 1 & 5.826 & 46.741 & .000 & .060 \\
\hline & Diffusion & 1.130 & 1 & 1.130 & 11.045 & .001 & .015 \\
\hline \multirow[t]{4}{*}{ Grade } & Achievement & .204 & 3 & .068 & .918 & .432 & .004 \\
\hline & Moratorium & 1.073 & 3 & .358 & 4.830 & .002 & .019 \\
\hline & Foreclosure & 4.143 & 3 & 1.381 & 11.081 & .000 & .043 \\
\hline & Diffusion & .171 & 3 & .057 & .557 & .642 & .002 \\
\hline \multirow[t]{4}{*}{ Gender ${ }^{*}$ Grade } & Achievement & .441 & 3 & .147 & 1.987 & .114 & .008 \\
\hline & Moratorium & .138 & 3 & .046 & .622 & .601 & .003 \\
\hline & Foreclosure & .799 & 3 & .266 & 2.136 & .094 & .009 \\
\hline & Diffusion & .964 & 3 & .321 & 3.142 & .025 & .013 \\
\hline \multirow[t]{4}{*}{ Error } & Achievement & 54.143 & 732 & .074 & & & \\
\hline & Moratorium & 54.204 & 732 & .074 & & & \\
\hline & Foreclosure & 91.239 & 732 & .125 & & & \\
\hline & Diffusion & 74.882 & 732 & .102 & & & \\
\hline
\end{tabular}

Table 4: Results of Multivariate Analysis of Variance for the effects of multi-function according to the value of the "F" computed on Wilks Lambda.

Table 4 indicates also the calculated value $(\mathrm{F})$ in the variable of grade is statistically significant at a standard of less than (0.05) in the two statuses of (moratorium and foreclosure). The Scheffe Test was applied to recognize the variance resources in the statuses of moratorium and foreclosure. The results of the Scheffe test proved the following: there are statistically significant differences for the students of the lower grades, 8-9 in comparison with the higher grades 10-11 in moratorium of the status and foreclosure ideological identities.

Table 4 has also shown differences in ideological identity diffusion status, which has a statistical significant at a standard less than (0.05) attributed to the interaction between gender and grade. The study's results show that males have more diffusion in grade 8 , that average was 1.998 in comparison with the males in the other grades, 9-10-11. While females were more inclined to diffusion in grade 11, and their mean was 1.891 in comparison with the other grades. But the effect of the interaction between gender and grade in ideological identity diffusion status, in spite of its significance was small as is shown by Partial Eta Squared (1.3\% of variance).

\section{Discussion}

The results of the first question showed that the status owned by the students of grades 8-11in Muscat governorate and the most common, is the achievement status. The researchers believe that this status of achievement is actually a status of moratorium that is transformed into the status of achievement or foreclosure. This is referred to by the study of [6]. As [8] confirms, the achieved identity cannot be achieved once and for all, as mentioned; individuals have less interest in their identities before secondary school. Even during this stage, the identity of the growth is lower than the overall belief, not up to the university or college even show identity clearly among students. The study by [14] suggested that achievement statuses are the statuses when the student passes the stage of exploration and search and he has clear and certain pledges and commitments. While in the statuses of moratorium, the student passes a stage of exploration and search but his commitments are vague and his performance in many of the measures is similar to the performance of his peers in the statuses of achievement.

The study results revealed that there are differences in the ideological identity statuses due to the variable, gender, that there is a difference in achievement status for females and differences in the statuses of foreclosure and diffusion for males. And that could be explained as the Omani society does not differentiate between the genders in education and treatment. It also provides males and females with equal opportunities both at the level of family and school. That leads to high self-esteem in females. The study results of [19] indicated that the ideological identity of females develops more strongly than that of males because of their ability to adjust with the state of maturity and their awareness of social relations. The most important aspect in achieving the identity of females is the relationships with others and family formation. The researches show that the status of achievement in females in the current study may be basically foreclosure as a result of the succession of the ideological identity and the transition from foreclosure to achievement [15] mentioned that foreclosure of identity and its achievement for females have nearly the same positive effects. The female feels safety and reassurance and does not feel worried and has strong commitments whether she was at the status of achievement or foreclosure. The current study explains the presence of males in the least natural statuses as males have a lot of frustration due to their negative estimation of self and lack of experience in the economic, educational and political conditions of their society. One is their belief in the lack of job opportunities which suit them. That leads to the prevalence ratio of job seekers.

The study's results have shown differences in identity statuses because of the variable of grade. These differences were in the statuses of moratorium and foreclosure for grades 8-9 compared with grades 10-11 and this result can be explained by the development in school years increases the presence of identity achievement statuses and the 
Page 6 of 7

statuses of moratorium and foreclosure disappear relatively speaking. The expertise that the student passes between grades 8-11 and the commitments he faces, make him do an accurate estimate of his personal needs and available abilities. So he begins to specify the best aspect intellectually and professionally and introduces private alternatives to the personal relations in the family and school contexts $[26,17]$.

The study also showed that there are differences in the status of identity diffusion because of the interaction between gender and grade, the males of grade 8 were more diffusion oriented and that is according of the supposition of Arker and Waterman that students of early adolescence (grade 8-9 in the current study) has not the cognitive ability for abstract thinking according to Piaget's theory and which helps him in the process of search and exploration of identity. That is because he is unable to make comparisons between alternatives in spite of the available information, he has. He is unable also to activate his skills and abilities. So it is difficult for him to achieve identity in his early adolescence. The girl students in grade 11 were more diffusion oriented because of the contradictory treatment by others in the society. The increase of the contradictory situations leads to the disorder of role and feeling of identity crisis [6]. The most of students' diffusion and confusion puts him in opposing positions of his estimate of his self-esteem allowing him to move freely and blame himself for getting out of traditions, norms and customs. Sometimes he is treated as an adult and sometimes as a child who has the duties of obedience [13].

\section{Limitations and Suggestions for Future Research}

Although this study has attempted to provide a somewhat detailed snapshot of identity differences among college students, there are a number of limitations that should be addressed in future studies. Firstly, all of the data were self-reported. Most studies have indicated such as the study of [25] to weaknesses of their evaluation because it does not give a true picture of the individual. It is better to use mixed methodology research when studying the subject of identity. Secondly, although this study represents an important advance in the understanding of ideological identity development from a lifespan perspective, some questions remain. Because these data were not longitudinal these findings cannot speak to developmental trajectories over time. In the future, it would be interesting to follow the intra individual changes in ideological identity across time to identify profiles or trajectories of change. For example, are individuals who develop achieved identities earlier in life more likely to remain stable across time? Are these same individuals more likely to report stable ideological identity content over time? Are some statuses more stable than others? Does this vary by age group? Therefore using longitudinal studies to examine these shifts in cases of identity; whether within the same individual or between the individual and the other is better. Thirdly, the researchers agree in this study with $[13,24]$ that examining the ideological content areas of identity (Occupational, political and religion, lifestyle) separately provides greater clarity on the nature of identity formation than does the report of an overall identity status.

In conclusion, the present study is an initial attempt to investigate the forms of ideological identity of Omani students, through knowledge of statuses of identity used in dealing with the psychological and social data in the culture and environment of Oman.

\section{Conflict of Interest}

The Authors declare no conflict of interest.

\section{References}

1. Erikson E (1969) Identity, youth and crisis. 14: 151-159.

2. Erikson E (1959) Identity and the life cycle. Psychological Issues1-171.

3. Yasemin A (2007) Identity Status of Turkish university students in relation to their evaluation of family problems. Soc Behav Pers 35: 79-87.

4. Eryigit S (2010) Identity Formation in Context (Unpublished doctoral dissertation). Auburn University Alabama.

5. Coffin D (2008) Young adult children of interfaith parents: Ego-identity development (Unpublished doctoral dissertation). At Alliant International University, San Diego.

6. Meeus W, ledema J, Helsen M, Vollebergh W (1999) Patterns of Adolescent Identity Development: Review of Literature and Longitudinal Analysis. Develop Rev 19: 419-461.

7. Romi S, Simcha G (2009) Ego identity and perceived family functioning: comparing at-risk native-born and immigrant Ethiopian adolescents in Israel. Adolescence 44: 869-890.

8. Marcia JE (1966) Development and validation of ego-identity status. J Pers Soc Psychol 3: 551-558.

9. Marcia JE (1967) Ego identity status: relationship to change in self-esteem "general maladjustment," and authoritarianism. J Pers 35: 118-133.

10. Hofer J, Chasiotis A, Kiessling F, Busch H (2006) Quality of Familial Relations in Childhood and Ego Identity Formation: The Moderating Influence of Dispositions of Action Control. Int J Theo Res 6: 117-140.

11. Schwartz S, Beyers W, Luyckx K, Soenens B, Zamboanga B, et al. (2011) Examining the light and dark sides of emerging adults' identity: A study of identity status differences in positive and negative psychosoctioning. J Youth Adolesc 40: 839-859.

12. Demetri BC (2008) Young adult children of interfaith parents: Ego-identity development (Unpublished doctoral dissertation). Alliant International University, San Diego.

13. Dwairy M (2004) Internal- structural validity of objective measure of ego identity status Among Arab Adolescents. Int J Theo Res 4: 1331-44.

14. Campbell J (2007) Adolescent Identity Development: The Relationship with Leisure Life Style and Motivation (Unpublished Master dissertation). University of Waterloo, Ontario, Canada.

15. Adams G, Fitch S (1982) Ego Stage and identity status development: A cross- sequential analysis. J Person Soc Psyc 43: 574-583.

16. Wires JW, Barocas R, Hollenbeck AR (1994) Determinants of adolescent identity development: a cross-sequential study of boarding school boys. Adolescence 29: 361-378.

17. Meeus W, Schoot R, Keijsers L, Schwartz S, Branje S (2010) On the Progression and Stability of Adolescent Identity Formation: A Five-Wave Longitudinal Study in Early-to-Middle and Middle-to-Late Adolescence. Child Dev 81: 1565-1581.

18. Lewis $H$ (2003) Differences in ego identity among college students across age, ethnicity and gender. Identity: Int J Theor Res 3: 159-189.

19. Alberts C (2000) Identity formation among African late-adolescents in a contemporary South African context. Int J Adv Couns 22: 23-42.

20. Echabe A (2010) Role identities versus social identities: Masculinity, femininity, instrumentality and communality. Asian J Soc Psy 13: 30-43.

21. Bennion L, Adams G (1986) A Revision of the Extended Version of the Objective Measure of Ego Identity Status: An Identity Instrument for Use with Late Adolescents. J Adoles Res 1: 183-197.

22. Luyckx K, Schwartz S, Berzonsky M, Soenens B, Vansteenkiste M, et al (2008) Capturing ruminative exploration: Extending the four-dimensional model of identity formation in late adolescence. J Res Person 42: 58-82. 
Citation: Al-Balushi BS, Alzubaidi AS, Kazem AM (2015) Ideological Identity Statuses of Students of Grades 8-11. Int J Psychol Behav Anal 1: 106. doi: http:// dx.doi.org/10.15344/2455-3867/2015/106

Page 7 of 7

23. Cakir SG, Aydin G (2005) Parental attitudes and ego identity status of Turkish adolescents. Adolescence 40: 847-859.

24. Bergh S, Erling A (2005) Adolescent identity formation: a Swedish study of identity status using the EOM-EIS-II. Adolescence 40: 377-396.

25. Solomontos-Kountouri O, Hurry J (2008) Political, religious and occupational identities in context: placing identity status paradigm in context. J Adolesc 31: $241-258$.

26. Graf SC, Mullis RL, Mullis AK (2008) Identity formation of United States American and Asian Indian adolescents. Adolescence 43: 57-69.

27. Alkhawaja A (2011) The Efficacy of a Vocational Guidance Program in Improving the Vocational Maturity and Adjustment of the Sultan. J Edu Psy Sci 12: 39-63.

28. Mcmillan J, Werging J (2002) Understanding and Evaluating Educationnal Research. Ohio: Merrill Prentice Haall. 